\title{
Gender Bias in Academic Medicine
}

Kathryn V Horn

\begin{abstract}
While more women graduate from medical school, there is still unequal representation of women in academic medicine, especially in the senior levels of academia. Gender bias is a strong reason women leave academic medicine. Disparities in salary and promotion, conscious and unconscious bias and institutional policies create a culture that does not favor their recruitment and retention. This article reviews literature that describes the problem and potential solutions to individuals, departments and institutions.
\end{abstract}

Keywords: Faculty, Medical/organization and administration, Physicians, Women, Gender bias, Prejudice, Sexism, Career choice.

How to cite this article: Horn KV. Gender Bias in Academic Medicine. Donald School J Ultrasound Obstet Gynecol 2014; 8(1):97-99.

Source of support: Nil

Conflict of interest: None

\section{INTRODUCTION}

In the United States women make up close to half of all medical school graduates but despite the increased representation of women entering medicine, there is still unequal representation of women in academic medicine. This paper draws from a number of resources to delineate the reasons women enter academic medicine, why they do not rise in the ranks and what solutions may assist in correcting this inequity.

In a 2011 article in the AAMC Reporter, Barbara Gabriel reported on the AAMC numbers from 2009 to 2010, that showed $35 \%$ of all faculty were women but $42 \%$ were assistant professors, $31 \%$ were associate professors and $19 \%$ were full professors. In leadership positions, $21 \%$ of division or section chiefs were women, $13 \%$ of chairs and $13 \%$ of deans. ${ }^{1}$ When one section of the population is not well represented in the academic setting, there is an impact on education, research and patient care. Women bring a different perspective and that potential to impact healthcare

Associate Dean

Office of Student Affairs, Paul L Foster School of Medicine, Texas Tech University Health Sciences Center at EI Paso, Texas, USA

Corresponding Author: Kathryn V Horn, Associate Dean for Student Affairs, Paul L Foster School of Medicine, Texas Tech UniversityHealthSciences Center, 5001 ElPasoDrEIPaso, TX79905 USA, Phone: 9152154366, e-mail: kathryn.horn@ttuhsc.edu should be nurtured. ${ }^{2}$ Lack of women mentors in academic healthcare can have an effect on future women choosing academic careers and lead to more attrition. ${ }^{3}$

Women choose academic medicine for a number of reasons. They may have been exposed to role models during medical school or residency that shared their satisfaction with academic medicine. ${ }^{4}$ Quality of life is seen as better in academic medicine compared to private practice. The earning potential is favorable and they value organizational reward for faculty members. ${ }^{5}$ Some women faculty may enter academics to pursue research although men who participate in research in medical schools are more likely to enter academic medicine than women. ${ }^{6}$ Women are less interested in leadership or national recognition when they enter academic medicine and may not have the same self confidence in their own abilities as their male counterparts. ${ }^{7}$

A study at the University of Minnesota examined why the number of women decreased over the span of graduation from medical school to attaining the rank of professor. ${ }^{8}$ More women leave academic medicine than men. The women in their study discussed a number of limiting factors: lack of collegiality, their relationship with the chair, department climate, salary, promotion and tenure process, institutional recognition and support, autonomy, stress, time constraints and intrinsic components of the work. ${ }^{8}$

Gender bias seems to be a strong reason to leave academic medicine. In a study titled: 'A Ton of Feathers: Gender Discrimination in Academic Medical Careers and How to Manage It', the authors interviewed women who had experienced gender discrimination. ${ }^{3}$ They found that women felt ill prepared to deal with gender discrimination. Often it was multiple 'small' things that led to the faculty feeling that they had experienced discrimination. Once women experienced gender bias, they found they had less confidence in achieving promotion and it was difficult to separate their abilities from limitations that they may have had secondary to family responsibilities. The hierarchical structure with few women at the top and the lack of recognition of the problem by male leaders contributed to their sense of isolation. In a Japanese study, the psychological effect of experiencing this type of bias decreased work motivation and women physicians who experienced gender discrimination were more likely to change to part time status. ${ }^{9}$ 


\section{Sources of Disparities}

Salary and promotion bias have been discussed in numerous studies. ${ }^{8-10}$ Men are more likely to be promoted to associate professor or higher, get higher salaries and have more publications and grants. Women with comparable credentials to men have a lower promotion rate. ${ }^{10}$

This may be due to an unconscious gender bias. Men are often unaware that they are biased. ${ }^{11,12}$ But studies show that male and female interviewers are biased toward a male if the name on the CV is a man's. ${ }^{11,13}$ Other examples of bias include a condescending attitude by male colleagues and unequal or disrespectful attention in meetings. Business literature reveals that leaders are valued when they are assertive but women who are seen as assertive are also considered less personable. ${ }^{12,14}$ It seems women may be viewed as competent or likeable but not both! ${ }^{12}$ Likeable leaders are viewed as more effective and have more followers. ${ }^{12}$ The lack of mentoring and of peer networks makes it harder for women to be prepared for the bias as it is experienced.

Another hurdle for women faculty to address is on the personal front. Women spend twice as much time as men on family and household activities; male faculty are less likely to have a full time working partner. ${ }^{8}$ In the Japanese study full time female doctors are more likely to be single and childless. ${ }^{9}$ Women site lack of extended family, expensive child care, short maternity leaves ${ }^{15}$ as further hindrances. Overall, time out for family or maternity leave is seen as a negative and a barrier toward advancement. ${ }^{10}$

There are institutional policies and practices that may also contribute to a feeling of bias by women. ${ }^{8}$ Part time policies and pregnancy leave is seen as burdensome to the other faculty members in the department which would contribute to a strained departmental atmosphere. Work demands that interfere with family time such as evening and weekend meeting times may unfairly target women who have family demands that prohibit participation at those times. Lack of onsite daycare has also been seen as a limiting factor. ${ }^{8}$

\section{Solutions}

Solutions can be applied at three levels - the individual faculty, the department and the institution. There are programs that are designed to provide women faculty with more skills to navigate academic medicine. These range from early career support (AAMC Early Career Women Faculty Professional Development Seminar) to midcareer (AAMC Mid-Career Women Faculty Professional Development Seminar) to those in leadership positions (Executive Leadership in Academic Medicine (ELAM) offered through the International Center for Executive Leadership in Academics at Drexel University). ${ }^{16}$

ELAM is a premier program designed to train women in skills that will allow them to stay the course in academics such as conflict resolution, training in negotiation, and strategic financing as well as the ability to lead organizational change. Individual career coaching and advice are offered during their time as fellows. This yearlong fellowship provides a network for women nationally and internationally. It also promotes inter-professional development as fellows are from medicine, dentistry and public health. Women are nominated by their Deans or CEO's and must receive yearlong support to attend the fellowship. Their program has been successful in assisting women as they move up the academic ladder. ${ }^{17}$

Male and female faculty can be educated to the pitfalls of unconscious bias. The AAMC's e-learning seminar on unconscious bias has many resources to assist in training individuals, search committees or whole departments. ${ }^{18}$ Most people who participate in the implicit association test are surprised at their own unconscious bias but awareness may assist in avoiding the behavior. ${ }^{13}$ Other tools, such as an objective structured interview process, setting criteria for skills needed for a position and awareness of bias created by a time pressured process allows individuals and departments to avoid the pitfalls of gender bias. ${ }^{13}$

Institutions can devote attention and resources to improving the retention of women faculty and avoiding gender bias that may precipitate their departure. Policies can be improved to address personal challenges faced by women faculty: child and elder care availability, onsite and emergency daycare and parental leave policies. ${ }^{8}$ Part time tenure track or stopping the tenure clock are also ways to support women who have family responsibilities that may distract them from the traditional pathway to promotion. ${ }^{8,19}$ Quality mentoring offered to women can assist them in identifying their own goals so that they are invested in their future in academic medicine. ${ }^{8}$ And, an atmosphere that honors team work over the individual's accomplishments can allow for more women's involvement in research and scholarly activities. ${ }^{19}$

The first step to understanding a culture that is conducive to academic success for women is to measure what is there. Such an instrument is described in 'A Culture Conducive to Women's Academic Success: Development of a Measure'. ${ }^{20}$ Their instrument looks at four areas for a conducive environment: equal access, work-life balance, freedom from gender bias and supportive leadership. This type of instrument could be very helpful for evaluating the atmosphere in a division, department or institution. Since department climate is one of the reasons that women leave 
academics, improving that climate may improve retention and satisfaction of women faculty members.

The University of Pennsylvania School of Medicine has established a gender equity committee. ${ }^{19}$ This committee oversees and monitors institutional progress toward recruitment and retention of women faculty. Senior women who serve as both role models and mentors meet with prospective recruits. They developed a resource packet for incoming women to describe community resources such as day care options as well as policies relating to family friendly issues. They also look for best practices on peer mentoring and support at the institutional and departmental levels. They seek to understand individual department climate by developing focus groups in those departments.

Another step toward improving peer networks and mentoring is to establish a local GWIMS chapter. AAMC Group on Women in Medicine states its mission is, "to advance the full and successful participation of women in all roles within academic medicine, and to provide a venue for women to participate in advancing the AAMC mission to improve the nation's health. ${ }^{, 21}$ A local chapter can provide a network of women who can share experiences, ideas and resources for awareness of bias and tools to improve the local culture for women faculty. At institutions in other countries, a local group of women to promote networking, peer support and institutional awareness can serve the same purpose.

\section{CONCLUSION}

The number of women entering medicine has come close to becoming gender neutral but if this is to continue, female medical students need role models and mentors to show them the path toward success in academic medicine. By educating individuals, men and women, improving the department and institutional climate and adjusting the policies that support all faculty, there is hope that gender bias and discrimination may be reduced and eliminated over time. Awareness is the first step. Through many initiatives, women may learn to traverse the labyrinth that can hold them back. ${ }^{14}$

\section{REFERENCES}

1. Gabriel BA, Lonely at the Top: Academic Medicine's Women Leaders AAMC Reporter: May 2011. Available at: https:// www.aamc.org/newsroom/reporter/may11/188562/lonely.html (Accessed on July 26, 2013).

2. Pololi LH, Jones SJ. Women Faculty: An analysis of their experiences in academic medicine and their coping strategies. Gend Med 2010;7(5):438-450.

3. Carr PL, Szalacha L, Barnett R, Caswell C, Inui T. A 'Ton of Feathers': Gender Discrimination in Academic Medical Careers and How to Manage It. J Womens Health 2003;12(10):1009-1018.
4. Cain JM, Schulkin J, Parisi V, Power ML, Holzman GB, Williams S. Effects of perceptions and mentorship on pursuing a career in academic medicine in obstetrics and gynecology. Acad Med 2001;76(6):628-634.

5. Borges NJ, Navarro AM, Grover A, Hoban JD. How When and Why do physicians choose careers in academic medicine? A Literature Review. Acad Med 2010;85(4):680-686.

6. Andriole DA, Jeffe DB. The Road to an Academic Medicine Career: A National Cohort Study of Male and Female US. Medical Graduates. Acad Med 2012;87(12):1722-1733.

7. Leonard JC, Ellsbury KE. Gender and interest in academic careers among first and third year residents. Acad Med 1996;71(5): 502-504.

8. Shollen SL, Bland CJ, Finstad DA, Taylor AL. Organizational Climate and Family Life: How These Factors Affect the Status of Women Faculty at One Medical School Acad Med 2009; 84(1):87-94.

9. Nomura K, Gohchi K. Impact of gender-based career obstacles on the working status of women physicians in Japan. Soc Sci Med 2012;75(9):1612-1616.

10. Flannery AM. Success, women and academic surgery. Surgery 2002;131(6):670-671.

11. Moss-Racusin CA, Dovidio JF, Brescoll VL, Graham MJ, Handelsman J. Science faculty's subtle gender biases favor male students. Proc Natl Acad Sci USA. 2012;109(41):16474-16479.

12. The double-bind dilemma for women in leadership: damned if you do, doomed if you don't. Available from: "http://www.catalyst.org. Accessed" www.catalyst.org (http://www.catalyst.org/uploads/ the_double_bind_for_women_in_leadership_flyer.pdf) Accessed January $10,2014$.

13. Corrice A. Unconscious bias in faculty and leadership recruitment: a literature review. Analysis in brief. AAMC 2009; 9(2). Available at: https://www.aamc.org/download/102364/data/aibvo19no2.pdf (Accessed on July 20, 2013).

14. Eagly AH, Carli LL. Women and the labyrinth of leadership. Harv Bus Rev 2007;85(9):62-71, 146.

15. Lundberg IE, Ozen S, Gunes-Ayata A, Kaplan MJ. Women in academic rheumatology. Arthritis Rheum 2005; 52(3):697-706.

16. ELAM Executive Leadership in Academic Medicine. Available at: https://www.drexelmed.edu/Home/OtherPrograms/ ExecutiveLeadershipinAcademicMedicine/AboutELAM.aspx (Accessed on July 20, 2013).

17. ELAMFast Facts. Available at: https://www.drexelmed.edu/Home/ OtherPrograms/ExecutiveLeadershipinAcademicMedicine/ AboutELAM/FastFacts.aspx (Accessed on July 26, 2013).

18. E-learning Seminar: What you don't know: The Science of Unconscious bias and what to do about it in the search and recruitment process. Available at: https://www.aamc.org/ members/leadership/catalog/178420/unconscious_bias.html (Accessed July 26,2013).

19. Morton MJ, Bristol MB, Atherton PH, Schwab CW, Sonnad SS. Improving the recruitment and hiring process for women faculty. J Am Coll Surg 2008;206(3):1210-1218.

20. Westring AF, Speck RM, Sammel MD, Scott P, Tuton LW, Grisso JA, Abbuhl S. A culture conducive to women's academic success: Development of a measure Acad Med 2012;87(11):1622-1631.

21. Group on women in medicine. Available at: https:/www.aamc. org/members/gwims/ (Accessed on July 26, 2013). 